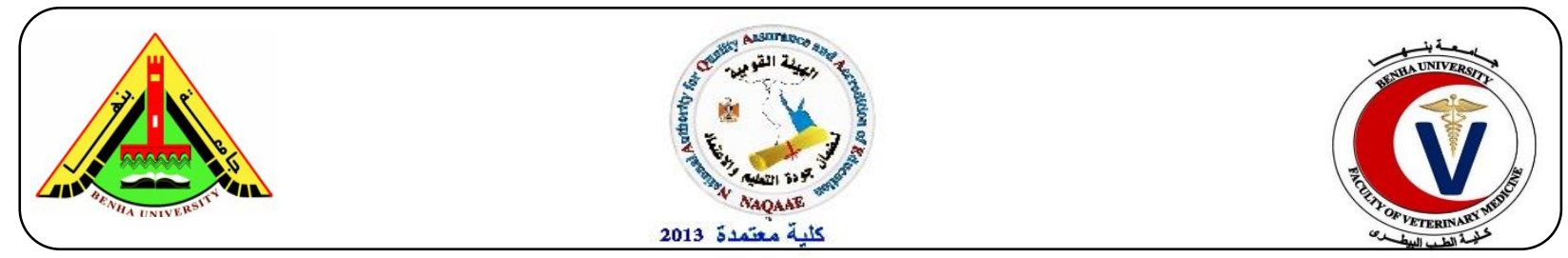

\title{
Omega-3 polyunsaturated fatty acids as therapeutic options for the treatment of ethanol induced gastric ulcer in rats
}

\author{
Yakout A. El Senosi ; Mohamed k. Mahfouz and Alaa Samy Ali Hussein
}

Biochemistry Department, Faculty of Vet. Med., Benha University, Egypt.

\begin{abstract}
A B S T R A C T
Gastric ulcer is a common chronic disease in human digestive system. Massive alcohol drinking can lead to gastric ulcer. In the present study we investigated the gastroprotective effect and the molecular mechanisms of Omega 3 polyunsaturated fatty acids( $\omega$-3 PUFAs) in a rat model of ethanol-induced gastric ulcer.42 male rats were divided into six equal groups. Group 1 :( Control normal group) rats received no drugs. Group 2 :( Omega-3 group): rats receivedOmega-3 orally(244.8 mg/kg b.wt/day) for 14 days. Group 3 :( early ulcer group):rats received absolute Ethanol $(0.5 \mathrm{ml} / \mathrm{rat})$ orallyand sacrificed one hour later after ethanol administration Group 4: (Early ulcer + Omega-3 protected group) rats received omega-3 similar to group 2 for 14 days prior to absolute ethanol administration, then sacrificed after one hour. Group5: (late ulcer group) rats received absolute ethanol similar to group 3 and sacrificed after 14 days. Group6:( Late ulcer + Omega-3 treated group)rats first administered with absolute ethanol then after one hour omega-3 was administered for 14 days. The results showed significant increase in No,L-MDA,GSH with marked decrease in CAT activity in stomachof ethanolinduced gastric ulcer in rats as compared with control normal group.However, a significant depletion of gastric tissue No, L-MDA and GSH concentrations and marked increase in CAT activity were observed after omega-3 treatment compared to ulcerated untreated rats. The qPCR results revealed a significant up-regulation of mRNA gene expression levels of TNF-a, MOP and iNOS in stomach of ethanol-induced gastric ulcer in rats. This expression was significantly down-regulatedafter administration of omega 3.Conclusively, omega-3 protects rat gastric mucosa against ethanol-induced gastric ulcer via anti-inflammatory and anti-oxidative mechanisms.
\end{abstract}

Keywords:Omega-3; ethanol, gastric ulcer; oxidative stress; anti-inflammatory

(http://www.bvmj.bu.edu.eg)

(bvmj, 34(1): $48-65$, MARCH, 2018

\section{INTRODUCTION}

Gastric ulcer is one of the commonest gastrointestinal pathologies affecting 4 million individuals annually worldwide. The risk of its occurrence has been reported to be increased by several etiological factors like alcohol consumption, prolonged use of non-steroidal anti-inflammatory drugs, stress and $H$. pylori infection (Thorsen et al., 2013). An imbalance in damaging and defensive factors has been considered as an important contributor to its pathogenesis where redox related damage and release of inflammatory mediators result in loss of mucosal integrity (Calam and Baron 2001). The acute phase of gastric ulceration involves 
composite action of inflammatory cytokines like tumor necrosis factor-alpha (TNF- $\alpha$ ), interleukins (IL-6, IL-10 and IL-1 $\beta$ ), over expression of p65 subunit of nuclear factorkappa B (NF- $\mathrm{BB}$ ) and the inflammation is further aggravated by the recruitment of inflammatory cells like neutrophils and mononuclear cells (Amirshahrokhi and Khalili 2015). The severity and maintenance of gastric damage also depends on the generation of free radicals that are highly reactive intermediates which bring about macromolecular changes (da Silvaa et al., 2013).

Alcohol consumption has been commonly linked to gastric mucosal lesions including gastritis, gastric ulcer and even gastric carcinoma (Franke et al., 2005). The mechanisms underlying ethanol-induced gastric ulcer have not been fully defined. Yet, mounting evidence has indicated that proinflammatory cytokines, oxidative stress and apoptosis play crucial roles in its pathogenesis (Al Batran et al., 2013). Invasion of gastric tissues by neutrophils, marked with increased myeloperoxidase (MPO) activity, contributes to gastric mucosal damage (Wallace et al., 1990). Activation of neutrophils is associated with an up-regulated inflammatory response with increased gastric expression of nuclear factor kappa B (NF-kB) which controls the generation of pro-inflammatory cytokines including tumor necrosis factor- $\alpha$ (TNF- $\alpha$ ). These events amplify the inflammatory cascade via triggering the release of other pro-inflammatory mediators and enhancing further recruitment of macrophages and neutrophils, thereby exacerbating the gastric insult (Sangiovanni et al., 2013). Meanwhile, oxidative stress has been implicated in the development of ethanolinduced gastric injury where an arsenal of reactive oxygen species (ROS) generated by activated leukocytes triggers mucosal damage via lipid peroxidation and via depletion of the antioxidant defenses such as reduced glutathione (GSH), glutathione peroxidase (GPx) and the total antioxidant capacity (TAC) (Liu et al., 2012). In the same context, enhancement of apoptosis and associated loss of mucosal epithelial cells are recognized as major players in the pathogenesis of ethanolevoked gastric damage (Al Batran et al., 2013).

Additionally, depletion of mucosal cytoprotective moieties, including prostaglandin E2 (PGE2) and nitric oxide (NO), has been intimately linked to ethanol consumption. The experimental model of ethanol-induced gastric injury mimics several features of the human condition and thus provides a mean for assessing agents with potential anti-ulcer actions along with their implicated mechanisms for gastric protection (Liu et al., 2012). In the clinical setting, the current approach for the management of gastric ulcers focuses on the use of proton pump inhibitors and $\mathrm{H} 2$ receptor antagonists as the mainstay treatment. However, administration of these drugs has been associated with several adverse effects such as nausea, constipation, gynecomastia and impotence that limit their use (Halabi et al., 2014). Thus, the search for effective agents with fewer side effects has been regarded as an effective strategy for the management of gastric ulcers. Previously, agents with antioxidant features have displayed beneficial actions in protecting against alcoholinduced gastric ulcer (Antonisamy et al., 2014).

An alternative treatment with fewer side effects that also reduces the inflammatory response and thereby reduces pain is believed to be omega-3 essential fatty acids ( $\omega$-3EFAs) found in fish oil (Maroon and Bost, 2006). Several mechanisms have been suggested to be 
involved in the gastroprotective effects of fish oil including a decrease in gastric acid secretion and lipid peroxidation as well as an increase in antioxidant enzymes during pylorus ligation and cold-restrain stress in rats (Bhattacharya et al., 2006). Docosahexaenoic acid (DHA) is an omega-3 long-chain polyunsaturated fatty acid present in fish oil.DHA possesses several actions such as anti-inflammatory, neuroprotectitve and cardioprotective effects (Mayurasakorn et al., 2011). DHA also inhibits dextran sulfate sodium-induced colitis in mice.Furthermore, DHA down regulates tumor necrosis factor alpha and interleukin 1-beta increased by colitis. Together, these findings suggest that DHA may be a pure compound of fish oil responsible for the gastroprotective actions(Cho et al., 2011). As inflammation and oxidative stress have been reported to play an important role in the pathogenesis of gastric ulceration, the present study was designed to evaluate the gastroprotective effect of omega-3 PUFAs in a rat model of ethanol-induced gastric ulcer. Parameters related to gastric damage,inflammation and oxidative stress were determined in order to elucidate some of the mechanisms behind $\omega$-PUFAs gastroprotective effect.

\section{MATERIALS AND METHODS}

\subsection{Experimental animals:}

Forty two white male albino rats, 4-5 weeks old and average body weight 110-130 g were used in the experimental investigation of this study. Rats were obtained from Laboratory Animals Research Center, Faculty of Veterinary Medicine, Moshtohor, Benha University. Animals were housed in separate metal cages, fresh and clean drinking water was supplied ad-libitum through specific nipple. Rats were kept at constant environmental and nutritional conditions throughout the period of experiment. The animals were left 14 days for acclimatization before the beginning of the experiment.

\subsection{Chemicals and drugs:}

The chemicals and drugs used in the present study were:

a- Omega-3 (fish oil):

Omega-3 fatty acids was manufactured by Puritan's Pride, INC. Holbrook,NY 11741 U.S.A. Omega-3 fatty acids present in a soft gelatin capsulated form with $1360 \mathrm{mg}$ in each capsule. Ester-omega fish oil $1360 \mathrm{mg}$ provides $950 \mathrm{mg}$ of total fatty acids comprising of EPA(Eicosapentaenoic acid) 625mg, DHA(Docosahexaenoic acid)244mg and other fatty acids. Omega-3 fatty acids were dissolved in propylene glycol and administered orally in a daily dose of $244.8 \mathrm{mg} / \mathrm{kg}$ body weight using stomach tube. Dose of omega-3 fatty acids was chosen to be within the therapeutic range levels reported in the pamphlet according to (Paget and Barnes, 1964).

b- Absolute ethyl alcohol (Ethanol):Ethyl alcohol was manufactured by SIGMAALDRICH Pharmaceutical Chemicals co.3050 Spruce Street and St Louis; Germany.

Induction of Gastric Ulcer:

Rats were fasted for 24 hours and allowed free access of water prior to the administration of ethanol for gastric ulcer induction. The gastric ulcers were induced in rats by administering absolute ethanol orally at a dose level of $(0.5 \mathrm{ml} / 100 \mathrm{~g}$ rat $)$, Mei et al., (2012) .

\subsection{Animal grouping:}


Rats were randomly divided into six main equal groups, 7 rats each, placed in individual cages and classified as follow:

Group 1: (Control Normal group): received no drugs, served as control non-treated for all experimental groups.

Group2: (Omega-3 normal treated group):Rats received omega-3(244.8 $\mathrm{mg} / \mathrm{kg} \quad$ body weight/day) orally for 14 days.

Group 3: (early ulcer non-treated group):Ratsreceived absolute ethanol $(0.5 \mathrm{ml} / \mathrm{rat})$ on empty stomach and weresacrificed after one hour later of ethanol administration.

Group 4: (Omega-3 protected group):Rats received omega-3 (244.8 $\mathrm{mg} / \mathrm{kg}$ body weight/day) orally for 14 successivedays prior to ethanol administration. One hour afteradministration of ethanol the animals were sacrificed.

Group 5:(late ulcernon-treated group):Ratsreceived absolute ethanol $(0.5 \mathrm{ml} / \mathrm{rat})$ on empty stomach and were left free and sacrificed 14 days later of ethanol administration.

Group6:(Omega-3 treated group): Ratsreceived absolute ethanol $(0.5 \mathrm{ml} / \mathrm{rat})$ on empty stomachat the first day of experiment and after one hour, omega-3 treatment $(244.8 \mathrm{mg} / \mathrm{kg}$ body weight/day) will be started for 14 successive days thensacrificed.

\section{4.sampling:}

Gastric tissue specimen were collected from all animal groups (control and experimental groups) onceafter the end of 2 weeks.

\subsubsection{Gastric tissue for biochemical analysis:}

After 14days of treatment with omega3 the rats were sacrificed by cervical decapitation. The stomach was quickly removed, and opened along the greater curvature using a scrapper, cleaned by rinsing with cold saline and stored at $-20^{\circ} \mathrm{C}$ for subsequent biochemical analysis.

Briefly, gastric tissues were cut, weighed and minced into small pieces, homogenized with a glass homogenizer in 9 volume of ice-cold $0.05 \mathrm{mM}$ potassium phosphate buffer (pH7.4) to make 10\% homogenates. The homogenates were centrifuged at 6000 r.p.m for 15 minutes at $4^{\circ} \mathrm{C}$ then the resultant supernatant were used for the determination ofL-Malondialdhyde (LMDA),Nitric oxide(NO) concentrations and catalase (CAT) activity.

Also, $0.2 \mathrm{gm}$ of stomach tissues were minced into small pieces homogenized with a glass homogenizer in $0.4 \mathrm{ml}$ of $25 \%$ metaphosphoric acid (MPA) (ref. No.: 253-4334, Sigma-Aldrich, Germany), then $1.4 \mathrm{~mL}$ of distilled water was added, mixed and incubated for 1 hour and centrifuged for $10 \mathrm{~min}$ at 3,000 r.p.m then the clean supernatant was removed and used for determination of GSH concentration.

\subsubsection{Gastric tissue for molecular analysis:}

At the end of experiment, and following sacrificing by decapitation, rats gastric tissue were immediately excised and frozen in liquid nitrogen and then in $-80^{\circ} \mathrm{C}$ until used for Tumor necrosis factor alpha (TNF- $\alpha$ ),Myeloperoxidase (MPO) and inducible nitric oxide synthase (iNOS)gene expression analysis by qPCR.

\subsection{Analysis:}

\subsubsection{Biochemical analysis:}

Gastric tissue L-malondialdehyde L(MDA), nitric oxide(NO), Catalase (CAT) and reduced glutathione(GSH )were determined 
according to the methods described by (Mesbahet al., 2004),(Montgomery and Dymock, 1961),(Xu et al., 1997) and(Patterson and Lazarow, 1955), respectively.

\subsubsection{Molecular analysis}

Total RNA was isolated from stomach tissue of rats using RNeasy Mini Kit (Thermo Qiagen, \#74104) according to the manufacturer's protocol. Following determination of RNA concentration and purity by Quawellnanodrop Q5000 (USA), $5 \mathrm{mg}$ of total RNA from each sample was reverse transcribed using Quantiscript reverse transcriptase. The produced cDNA was used as a template to determine the relative expression of Tumor necrosis factor alpha (TNF- $\alpha$ ), Myeloperoxidase (MPO) and inducible nitric oxide synthase (iNOS) genes using Step One Plus real time PCR system (Applied Biosystem, USA) and gene specific primers. The reference gene, $\beta$ actin, was used to calculate fold change in target genes expression. The thermal cycling conditions, melting curves temperatures, and calculation of relative expression was done. For the treated groups, assessment of $2^{-\Delta \Delta C t}$ determined the fold change in gene expression relative to the control.

Forward and reverse primers sequence for real time PCR.

\begin{tabular}{|l|l|l|}
\hline Gene & $\begin{array}{l}\text { Forward primer } \\
(\text { '5 ----- } 3)\end{array}$ & $\begin{array}{l}\text { Reverse primer } \\
(\text { '5 ----/3) }\end{array}$ \\
\hline$T N F \alpha$ & GCATGATCCGCGACGTGGAA & AGATCCATGCCGTTGGCCAG \\
\hline$i N O s$ & GACCAGAAACTGTCTCACCTG & CGAACATCGAACGTCTCACA \\
\hline$M P O$ & ACCTACCCCAGTACCGATCC & AACTCTCCAGCTGGCAAAAA \\
\hline$\beta$-actin & ACCCACACTGTGCCCATCTA & CGTCACACTTCATGATG \\
\hline
\end{tabular}

\subsection{Statistical Analysis}

For biochemical analysis the obtained data were analyzed using the statistical package for social science (SPSS, 13.0 software, 2009), for obtaining mean and standard deviation and error. The data were analyzed using one-way ANOVA to determine the statistical significance of differences among groups, followed by Duncan's test.

\section{RESULTS:}

Effect of omega-3 administration on gastric tissue NO, L-MDA, CAT and GSH of ethanol-induced gastric ulcer in male rats is presented in table (1).The obtained results showed significant increase in No, L-MDA and GSH concentrations with marked decrease in CAT activity in stomach of ethanol-induced gastric ulcer in rats as compared with control
However, for molecular analysis the difference between the groups was determined by one way ANOVA using GraphPad Prism 5 (GraphPad Software, Inc., LaJolla, CA, USA). Comparison of means was carried out with Tukey's Honestly Significant Difference (Tukey's HSD) test. Data were presented as mean SEM (standard error of mean) and significance was declared at $\mathrm{P}<0.05$.

normal group. However, a significant depletion of gastric tissue No, L-MDA and GSH concentrations and marked increase in CAT activity were observed after omega-3 treatmentcompared to ulcerated untreated rats.On the other hand, NO, CAT and GSH in omega-3 treated normal rats were non significantly increased and L-MDA 
concentration was slightly increased when compared with control normal group.

Effect of omega-3 administration on the relative mRNA expression of inflammationrelated genes, TNF-a,MPO and iNOSin stomach of ethanol-induced gastric ulcer in rats isshown in table(2). The obtained qPCR results revealed a significant up regulation of TNF- $\alpha$, MPO and iNOSgene expression levels in stomach of ethanol-induced gastric ulcerative rats (G3 and G5) as compared to control normal group (G1) and omega3 group (G2). This expression was significantly down regulated following administration of omega 3 either before (G4) or after (G6) induction of ulcer, with lower expression in preventive group (G4).However, the expression levels of TNF- $\alpha$ and MPO in the two treated groups (G4 and G6) remained significantly higher than that in G1 and G2. Unlike in G4, the expression level of iNOS gene expression in G6 remained significantly higher than that in G1 and G2. In addition, TNF- $\alpha$ and iNOS gene expression was significantly higher in G1 than G2. However, there was no significant difference in the expression of MPO gene between G1 and G2.

Table 1: Effect of omega-3 administration on gastric tissue NO, L-MDA, CAT and GSH of ethanolinduced gastric ulcer in male rats.

\begin{tabular}{|c|c|c|c|c|}
\hline $\begin{array}{l}\text { Parameters } \\
\text { Animal groups }\end{array}$ & $\begin{array}{c}\mathrm{NO} \\
(\mu \mathrm{mol} / \mathrm{g} . \text { tissue })\end{array}$ & $\begin{array}{c}\text { L-MDA } \\
\text { (mmol/ g. tissue) }\end{array}$ & $\begin{array}{c}\text { CAT } \\
(\mathrm{mmole} / \mathrm{min} / \mathrm{g} . \text { tissue })\end{array}$ & $\begin{array}{c}\text { GSH } \\
\text { (ng/g. tissue) }\end{array}$ \\
\hline $\begin{array}{l}\text { Group I: } \\
\text { Normal control }\end{array}$ & $23.55 \pm 1.94^{\mathrm{d}}$ & $2.93 \pm 0.17^{\mathrm{d}}$ & $2.21 \pm 0.10^{\mathrm{a}}$ & $4.70 \pm 0.29^{b c}$ \\
\hline $\begin{array}{l}\text { Group } \Pi \text { : } \\
\text { Omega-3 group }\end{array}$ & $26.26 \pm 2.19^{\mathrm{cd}}$ & $4.27 \pm 0.15^{\mathrm{c}}$ & $2.23 \pm 0.11^{\mathrm{a}}$ & $5.46 \pm 0.33^{b}$ \\
\hline $\begin{array}{l}\text { Group III: } \\
\text { Early ulcer group } \\
\text { Group IV: }\end{array}$ & $36.85 \pm 1.69^{a}$ & $6.73 \pm 0.34^{b}$ & $1.27 \pm 0.10^{c}$ & $6.58 \pm 0.08^{a}$ \\
\hline $\begin{array}{l}\text { Early ulcer + Omega-3 } \\
\text { protected }\end{array}$ & $31.76 \pm 1.15^{\mathrm{b}}$ & $2.90 \pm 0.15^{\mathrm{d}}$ & $1.86 \pm 0.08^{b}$ & $4.80 \pm 0.37^{b c}$ \\
\hline $\begin{array}{l}\text { Group V : } \\
\text { Late ulcer group } \\
\text { Group VI: }\end{array}$ & $36.55 \pm 0.67^{a}$ & $7.63 \pm 0.45^{\mathrm{a}}$ & $1.49 \pm 0.09^{c}$ & $3.84 \pm 0.35^{\mathrm{c}}$ \\
\hline $\begin{array}{l}\text { Late ulcer + Omega-3 } \\
\text { treated }\end{array}$ & $29.16 \pm 0.92^{\mathrm{bc}}$ & $4.10 \pm 0.06^{\mathrm{c}}$ & $2.04 \pm 0.02^{\mathrm{ab}}$ & $4.19 \pm 0.28^{c}$ \\
\hline
\end{tabular}

Data are presented as (Mean \pm S.E). $\quad$ S.E $=$ Standard error.

Mean values with different superscript letters in the same column are significantly different at $(\mathrm{P} \leq 0.05)$. 
Table (2): Effect of omega-3 administration on the relative expression of TNF- $\alpha$, MPO and iNOS gene in stomach of ethanol-induced gastric ulcer-induced in rats.

\begin{tabular}{|c|c|c|c|c|c|c|}
\hline \multirow{2}{*}{$\begin{array}{l}\text { Parameters } \\
\text { Animal groups }\end{array}$} & \multicolumn{2}{|c|}{$\begin{array}{l}\text { Tumor necrosis factor } \\
\text { alpha (TNF- } \alpha)\end{array}$} & \multicolumn{2}{|c|}{ Myeloperoxidase (MPO) } & \multicolumn{2}{|c|}{$\begin{array}{l}\text { Inducible nitric oxide } \\
\text { synthase (iNOS) }\end{array}$} \\
\hline & $\begin{array}{l}\text { Fold change } \\
\text { mean }\end{array}$ & SEM & $\begin{array}{l}\text { Fold change } \\
\text { mean }\end{array}$ & SEM & $\begin{array}{l}\text { Fold change } \\
\text { mean }\end{array}$ & SEM \\
\hline $\begin{array}{l}\text { Group I: } \\
\text { Normal control }\end{array}$ & $1.00^{\mathrm{e}}$ & 0.02 & $1.00^{\mathrm{d}}$ & 0.02 & $1.00^{\mathrm{c}}$ & 0.02 \\
\hline $\begin{array}{l}\text { Group П : } \\
\text { Omega-3 group }\end{array}$ & $0.44^{\mathrm{f}}$ & 0.02 & $0.99^{d}$ & 0.08 & $0.32^{\mathrm{d}}$ & 0.01 \\
\hline $\begin{array}{l}\text { Group III: } \\
\text { Early ulcer group }\end{array}$ & $4.03^{b}$ & 0.21 & $4.11^{\mathrm{a}}$ & 0.25 & $2.51^{\mathrm{b}}$ & 0.12 \\
\hline $\begin{array}{l}\text { Group IV: } \\
\text { Early ulcer + } \\
\text { Omega-3 } \\
\text { protected }\end{array}$ & $2.20^{d}$ & 0.06 & $2.01^{\mathrm{b}}$ & 0.08 & $1.11^{\mathrm{c}}$ & 0.05 \\
\hline $\begin{array}{l}\text { Group V : } \\
\text { Late ulcer group }\end{array}$ & $6.28^{\mathrm{a}}$ & 0.34 & $4.14^{\mathrm{a}}$ & 0.23 & $4.03^{\mathrm{a}}$ & 0.25 \\
\hline $\begin{array}{l}\text { Group VI: } \\
\text { Late ulcer }+ \\
\text { Omega-3 treated }\end{array}$ & $3.14^{\mathrm{c}}$ & 0.06 & $2.81^{\mathrm{c}}$ & 0.1 & $2.50^{\mathrm{b}}$ & 0.09 \\
\hline
\end{tabular}

Means within the same column carrying different superscript letters are significantly different $(\mathrm{P} \leq$ $0.05)$.

\section{DISCUSSION}

Ethanol is an ulcerogenic agent that is known to produce erosions, ulcerative lesions, and petechial bleeding in the mucosa of the stomach. Ethanol rapidly penetrates the gastric mucosa, causing membrane damage, exfoliation of cells, erosion, and ulcer formation (Franke et al., 2005). The obtained results showed significant increase in No, L-MDA and GSH concentrations with marked decrease in CAT activity in gastric tissue of ethanol-induced gastric ulcer in rats. Ethanol produced gastric ulcer through different mechanisms including generation of oxidative stress, initiation of lipid peroxidation and inflammation, infiltration of neutrophils, induction of apoptosis, and inhibition of prostaglandin E2 synthesis. Moreover, oxidative stress and inflammation are the key mediators in ethanol's gastric ulcer pathways. Ethanol provoked free radicals and depletion in antioxidant activities (Katary and Salahuddin, 2017).Nearly similar results were reported by (Mohod et al., 2016) who shown significant decreased in gastric SOD and GSH level after acetic acid administration in rats. Whereas MDA level was significantly increased. Also, Chellappan et al., (2016) reported that,a significant reduction in CAT activity and GSH level were observed in ethanol treated rats. However, Lipid peroxidation was significantly increased as compared with normal rats. Moreover, Verma and Kumar (2016) reported that, ulcer induction with ethanol administration and pylorus ligation showed a marked reduction in the level of GSH and activity of SOD and increase in the levels of TBARS and MPO in ethanol group when 
compared to normal control.Alcohol causes severe oxidative stress in gastric tissue, which is manifested as an enhancement in lipid peroxidation that occurs via an increase in the MDA content and a decrease in the gastric GSH content (Cadirci et al., 2007). Lipid peroxidation is a major outcome of free-radicalmediated injury, which causes immediate damage to the cell membrane and is related to DNA damage (Fortunato et al., 2006). MDA is a final product of lipid peroxidation, and its level is commonly measured as an indication of lipid peroxidation levels in tissues (Dursun et al., 2009). GSH, the most abundant antioxidant in cells, plays a major role in the defense against oxidative stress-induced cellular injury and is essential for the maintenance of the intracellular redox balance (Dey and Cederbaum, 2006). Consistent with previous results, the administration of ethanol significantly increased the concentration of MDA and decreased that of GSH in the gastric tissues. Furthermore, the levels of antioxidant enzymes (CAT and SOD) were markedly reduced in the ethanol-treated group compared to the normal control group. Moreover, 0xidative stress is brought about by the generation of free radicals and reactive metabolites like superoxide, nitric oxide, hydroxyl radical, hydrogen peroxide which are unstable byproducts of electron transfer reactions and are highly reactive with cellular macromolecules. Gastric damage is associated with increased generation of superoxide anions which under acidic conditions of the stomach, impair mitochondrial oxidative phosphorylation and result in cellular lipid peroxidation and apoptosis of mucosal cells independent of the involvement of cyclooxygenase (Nagano et al., 2012).As a result, the free radical scavenging effect of non enzymatic and enzymatic antioxidants gets diminished that leads to mucosal damage (Sen et al., 2013).

Nitric oxide is a potent vasorelaxant involved in the control of the gastric blood flow and is a gaseous mediator contributing to the maintenance of gastric mucosal integrity (Kwiecien et al.,2012).Ethanol increased free radical production and blunted nitric oxide in the gastric mucosa, resulting in gastric mucosa damage (Salga et al., 2012).NO is a major product which is controlled by nitric oxide synthases (NOSs), such as inducible NOS (iNOS), endothelial NOS, and neuronal NOS. Most importantly, highly expressed iNOS could lead to organ destruction in some inflammatory and autoimmune diseases. NO could lead to oxidative burst, which would inflict endothelial damage. Moreover, the enhanced generation of NO by iNOS may contribute to the pathogenesis of various gastroduodenal disorders including peptic ulcer (Souza et al., 2004).Cho, (2001) demonstrated that nitric oxide (NO) generated from inducible nitric oxide synthase (iNOS) participates in ulcer formation through the production of peroxide free radicals and their cytotoxic action. The enhanced generation of NO by the iNOS might contribute to the pathogenesis of various gastroduodenal disorders including peptic ulcer (Souza et al.,2004).An increase in iNOS activity in the gastric mucosa was closely related to the development of gastric mucosal lesions. Ethanol ingestion could induce severe gastric mucosal damage by increasing the expression of the pro-inflammatory mediators such as iNOS mRNA (Luiz Ferreira et al.,2012). When NO is generated at micromolar concentrations by the inducible form (iNOS), it promotes mucosal injury by enhancing 
apoptosis and inflammation (Calatayud et al., 2001).

In the current study a significant depletion of gastric tissue No, L-MDA and GSH concentrations and marked increase in CAT activity were observed after administration of $\omega$-3 PUFAs in gastric ulcerinduced rats. Similarly, Mohammed et al. (2012) showed that n-3 PUFAs reduce iodoacetamide-induced gastritis in rats by decreasing malondialdehyde (MDA), gastrin and nitric oxide (NO), and normalizing mucosal glutathione. Fish oil (FO) has previously been shown to positively influence antioxidant status in tissues and plasma by increasing the activity of ROS scavenging antioxidant enzymes and inhibiting LPO (Bhattacharya et al., 2005). Therefore, inhibition of LPO and increase in activity of free radical scavenging antioxidant enzymes could also be one of the mechanisms involved in the beneficial effect of FO in preventing gastric ulceration.

Treatment with omega-3 significantly reduced the malondialdehyde (MDA) concentration level, an indicator of lipid peroxidation, and also significantly increased the reduced antioxidant enzyme activities in the stomach homogenates, most likely by inhibiting the production of lipid peroxides from fatty acids in the stomach. The reduction in MDA by omega-3 in response to the oxidative stress in rats might be because of the antioxidant effect of the omega-3 in the stomach homogenate, where the severe damage to the mucous membranes caused by ethanol is prevented. The significantly decreased levels of MDA in rats which taken omega-3 might be due to the decreased oxidative gastric damage (Rozza et al.,2014).Additionally, gastroprotective effects of fish oil have been reported in gastric ulcers induced by ethanol (Leung, 1994). Several mechanisms have been suggested to be involved in the gastroprotective effects of fish oil, including a decrease in gastric acid secretion and lipid peroxidation as well as an increase in the levels of antioxidant enzymes during pyloric ligation and cold-restraint stress in rats (Bhattacharya et al, 2006). DHA is an n3 PUFAs present in fish oil. DHA exhibits several actions, such as anti-inflammatory, neuroprotectitve, and cardioprotective effects (Mayurasakorn et al., 2011). DHA also inhibits dextran sulfate sodium induced colitis in mice. Furthermore, DHA downregulates expression of tumor necrosis factor a and interleukin-1b increased by colitis (Cho et al., 2011). Together, these findings suggest that DHA may be a pure compound of fish oil responsible for the gastroprotective actions.

Furthermore, $\omega-3$ PUFAs paradoxically potentiate cellular antioxidant defense mechanisms. DHA inhibited the ROS and RNS production in murine macrophage cells stimulated with LPS (Ambrozova et al., 2010). DHA also diminished intracellular peroxide production and restored the levels of reduced glutathione (GSH) in RAW264 cells stimulated with interferon $\gamma$ (IFN $\gamma$ ) plus LPS (Komatsu et al., 2003). Like peroxide, nitric oxide (NO) produced by activated macrophages during infection plays a crucial role in host defense mechanisms via antimicrobial and cytoprotective activities. However, excess production of NO can cause tissue damage associated with acute and chronic inflammation. DHA inhibited the expression of inducible nitric oxide synthase (iNOS), an enzyme responsible for NO production, in LPStreated murine macrophage cells (Komatsu et al., 2003). Similarly, DHA inhibited NO production in murine macrophages stimulated by IFN $\gamma$ plus LPS, and this effect was 
associated with suppression of NF- $\mathrm{NBmediated}$ iNOS expression (Komatsu et al., 2003). These results strongly indicate that DHA exerts antioxidative as well as anti-inflammatory actions by reducing the intracellular accumulation of ROS and RNS, and maintaining optimal levels of GSH and antioxidant enzymes.

The obtained qPCR results revealed a significant upregulation of TNF- $\alpha, M P O$ and iNOSgene expression levels in stomach of ethanol-induced gastric ulcerative rats as compared to control normal group. It has been documented that experimental impairs gastric ulcers healing occurred via a mechanism involving an increase in expression and release of pro-inflammatory cytokines such as TNF- $\alpha$ and IL-1 $\beta$ (Sarkate et al., 2015). A high level of IL-1 $\beta$ (interlukin-1 $\beta$ ) and TNF- $\alpha$ (tumor necrosis factor- $\alpha$ ) from the gastric epithelium as well as neutrophils and macrophages have been reported to be overexpressed in the inflamed gastric mucosa (Yao, 2015). Similarly, Song et al., (2016) reported that ethanol treatment increased TNF- $\alpha$ expression in the gastric mucosa by 2.2 -fold.Also, the protein expression of iNOS was significantly increased after intragastric administration of ethanol compared with that observed in the normal control group. Also, Mohod et al ., (2016) shown a significant up-regulation in TNF- $\alpha$, IL-1 $\beta$, iNOsand COX-II mRNA expression in the pyloric antrum tissue of acetic acid treated rats as compared to normal control.Ingestion of ethanol induced the inflammatory response as verified by up regulation of gene expression and mucosal level of pro inflammatory cytokine TNF- $\alpha$ as well as elevation in mucosal levels of IL-1 $\beta$ and IFN $\gamma$ (Wang et al., 2016). Meanwhile, inflammatory cytokines TNF- $\alpha$, IL- $1 \beta$ and IFN $\gamma$ stimulate neutrophils and macrophages infiltration (Hasgul et al., 2014) as well TNF- $\alpha$ restrains gastric microcirculation around ulcerated mucosa and delays its healing (Lawrence, 2009). These results were consistent with other studies asKatary1 and Salahuddin (2017) who reported that, ingestion of ethanol up regulated protein expression levels of inflammatory cytokines TNF- $\alpha$, IL- $1 \beta$ and IFN $\gamma$ in addition to myeloperoxidase activity. Moreover, induction of gastric ulcer by ethanol significantly increasedmucosal expression of mRNA for COX-2, IL-1 $\square \square$ and TNF- $\square \square$ and Warzecha et al., (2014) who shown that, intragastric application of ethanol induces gastric mucosal damage and increases mucosal expression of mRNA for IL-1 $\square \square$ and TNF- $\square$. Both these cytokines are well known mediators of acute inflammation. IL-1 $\square \square$ plays a crucial role in the induction of systemic acute phase response and in the release of other members of the proinflammatory cytokine cascade such as TNF- $\square$, platelet activating factor (PAF), prostaglandins and pro-inflammatory interleukins (Dinarello, 2011). In addition to generating ROS, ethanol administration provokes an inflammatory response that releases numerous inflammatory cytokines, such as TNF- $\alpha$, IL-6, and IL- $1 \beta$ (Salga et al., 2012). TNF- $\alpha$ is a major inflammatory cytokine that is secreted by macrophages during inflammation and plays a key role in the induction of gastric mucosal damage (Rozza et al., 2014). TNF- $\alpha$ reduces the gastric microcirculation around an ulcer and delays gastric ulcer healing by potentiating the inflammatory response (Abdelwahab 2013). Elevated levels of IL-6 activate neutrophils, lymphocytes and monocytes/macrophages at the inflammatory site, which in turn initiates oxidative bursts, toxic metabolites, and the lysosomal enzymes responsible for local tissue 
damage in peptic ulcer disease( Mei et al., 2012).

In the current study the obtained qPCR results revealed a significant downregulation of TNF- $\alpha$, MPO and iNOSgene expression levels in stomach of ethanol-induced gastric ulcerative rats following administration of omega 3 either before or after induction of ulcer. Fish oils are rich sources of n-3 polyunsaturated fatty acids (PUFAs), especially eicosapentaenoic acid (EPA, 20:5 n-3) and (docosahexaenoic acid, DHA, 22:6 n-3). Several studies showed that dietary fish oil and n-3 PUFAs have immunomodulatory effects and therapeutic benefits in various diseases and metabolically stressed conditions (Chiu et al., 2007). Inflammatory lipid mediators and cytokines participate in the development of chronic lesions of Crohn's disease and ulcerative colitis (Thyssen et al., 1996). n-3 PUFAs may alter eicosanoid formation, thus reducing inflammatory cytokine generation(Wada et al., 2007). In addition, n-3 PUFAs influence the process of inflammatory cell activation that involves effects at the genomic level and signal transduction to protein expression (Grimm et al., 2002).

Dietary fish oil completely abolished mRNA for TNF- $\alpha$, IL-1 $\beta$, and IL- 6 in the kidneys of autoimmune disease-prone mice (Chandrasekar and Fernandes 1994). Fish oil lowered LPS-stimulated TNF- $\alpha$ mRNA levels in murine peritoneal macrophages (Renier et al., 1993). Because eicosanoids derived from AA regulate inflammatory gene expression, the effects of n-3 PUFA might come about through antagonism of the effects of AA-derived mediators. However, at least some of these effects have been demonstrated to occur in an eicosanoidindependent manner (de Caterina et al., 1994).
Recent studies indicate that n-3 PUFA exert some effects through direct actions on the intracellular signaling pathways that lead to activation of one or more transcription factors. Yoshihara et al., (2015) reported decreased expression of TNFaand inhibited macrophage-mediated inflammation in the aortas with administration of EPA and DHA. Furthermore, EPA derivatives have been used as a treatment of inflammatory diseases. The therapeutic effect of omega-3 was dependent on a decreased production of proinflammatory cytokines (Song and Horrobin 2004).

In the present study, treatment with ethanol significantly increased expression of MPO activity in gastric tissue when compared normal group. MPO activity was considerably increased in stomach after ethanol administration, which confirms neutrophils activation in gastric mucosa (Antonisamy et al., 2014).There is increasing resources suggested the ethanol administration stimulates neutrophil activation, oxidative stress through ROS formation, diminishing cellular oxidative defense, initiating ROS-mediated lipidperoxidation (Antonisamy et al., 2014). Inhibition of neutrophil infiltration in ulcerated gastric tissue is an important mechanism of antiulcer drugs against mucosal injuries (Ganguly et al., 2005). Moreover, MPO is peroxidase enzyme and central indicator of neutrophil infiltration in ulcerogenic injuries (Nishida et al., 1998). This enzyme is most abundantly expressed inside the neutrophils and produces hypochlorous acid $(\mathrm{HOCl})$ from hydrogen peroxide $\left(\mathrm{H}_{2} \mathrm{O}_{2}\right)$ and chloride anion (Cl) through oxidation process, which is detrimental to host tissues (Halliwell and Gutteridge, 2006). In this study MPO activity was considerably increased in stomach after 
ethanol administration, which confirms neutrophils activation in gastric mucosa. Omega 3 pretreatment significantly reduced MPO level in ulcerated rats, suggesting the ability of Omega 3 to prevent neutrophil infiltration in ulcerated gastric tissue.

Inducible nitric oxide synthase (iNOS) is expressed in the ulcer bed and that iNOS activity may play beneficial roles in the ulcer repair process, possibly by regulating inflammation (Tatemichi et al.,2003).In the current study high expression of iNOS was found in stomach tissue after gastric ulcer induction. Large amounts of NO synthesized from the inducible isoform have been implicated in tissue injury in the gut during inflammatory reactions (Barrachina et al., 2001). Guoet al.,(2003)also reported that high expression and activity of iNOS were found to coincide with severe inflammation in ulcer tissue. It is known that induction of high-output iNOS usually occurs in an oxidative environment, and thus high levels of NO have the opportunity to react with superoxide anion $\left(\mathrm{O}^{2-}\right)$ leading to peroxynitrite $\left(\mathrm{ONOO}^{-}\right)$ formation and cell toxicity, protein tyrosine nitration, hydroxyl radical production and tissue damage(Ding et al.,2005).Moreover, NO produced by inflammatory cells by the inducible isoform of NOS has antimicrobial, antitumor and cytotoxic effects, but the excessive amount may lead to peroxynitrite formation, protein tyrosine nitration, hydroxyl radical production and tissue damage (Kandhare et al., 2016). Nitrosative stress is an indispensable stress factor that plays a pivotal role in the aggravation of ulcers. iNOs is elevated in the gastric mucosa on account of enhanced nitrosative stress due to ulcers (Yang et al., 2008). Previous research reported that the enhanced ulcerogenic response is mediated by endogenous NO, mainly produced by iNOS (Nagai et al., 2009). It has been advocated that elevated iNOS levels corresponded to a loss of integrity of gastric mucosa and elevated gastrointestinal damage (Junior et al., 2014). This demonstrated that omega 3 might decrease NO production through inhibition of iNOS expression in the gastric ulcer tissue, prevent the abundant release of NO that aggravates gastric mucosal injury and, ultimately, improve the healing of ulcers.

\section{CONCLUSION:}

These findings suggest that oral treatment with omega-3 shows a significant gastroprotective effects in ethanol induced gastric ulcer models confirmed by antioxidant and anti-inflammatory activities. Also, the gastroprotective effect of omega-3 might be mediated by adjustment of inflammatory mediators and increasing antioxidants as well as attenuating oxidant/antioxidant imbalance. Moreover, omega-3 administration may have the potential as an alternative treatment for gastric ulcer because of its cytoprotective and anti-inflammatory effects.

\section{REFERENCES}

Abdelwahab ,S.I. 2013. Protective mechanism of gallic acid and its novel derivative against ethanol-induced gastric ulcerogenesis: Involvement of immunomodulation markers, Hsp70 and Bcl-2-associated $\mathrm{X}$ protein. Int. Immunopharmacol., 16, 296-305.

Al Batran, R., Al-Bayaty, F., Jamil Al-Obaidi M.M., Abdualkader, A.M., Hadi ,H.A., Ali, H.M., et al. 2013. In vivo antioxidant and antiulcer activity of Parkiaspeciosaethanolic leaf extract against ethanol-induced gastric ulcer in rats. PLoS One.; 8(5):e64751. 
Ambrozova, G., Pekarova, M., Lojek, A. 2010. Effect of polyunsaturated fatty acids on the reactive oxygen and nitrogen species production by raw 264.7macrophages, Eur. J. Nutr. 49 (3) 133-139.

Amirshahrokhi, K., Khalili, A.R. 2015 . The effect of thalidomide on ethanolinduced gastric mucosal damage in mice: Involvement of inflammatory cytokines and nitric oxide, Chem.Biol. Interact. (225) 63-69.

and defensive factors in gastric ulceration in rats. Prostaglandins Leukot Essent Fatty Acids74,109-116.

Antonisamy, P., Subash-Babu, P., Alshatwi, A.A., Aravinthan, A., Ignacimuthu, S., Choi, K.C., et al. 2014.Gastroprotective effect of nymphayol isolated from Nympha eastellata (Willd.) flowers: Contribution of antioxidant, antiinflammatory and anti-apoptotic activities. Chem Biol Interact. (224):157-163.

Barrachina, M.D., Panes,J.,Esplugues, J.V. 2001. Role of nitric oxide in gastrointestinal inflammatory and ulcerative diseases: perspective for drugs development. Curr Pharm Des; 7: 31-48.

Bhattacharya, A., Ghosal, S., Bhattacharya, S.K. 2006.Effect of fish oil on offensive and defensive factors in gastric ulceration in rats. Prostaglandins Leukot Essent Fatty Acids.;74(2):109-16.

Bhattacharya, A., Rahman, M., Banu, J., Lawrence, R.A., McGuff, H.S., Garrett, I.R., Fischbach, M., Fernandes, G. 2005. Inhibition of osteoporosis in autoimmune disease prone $\mathrm{MRL} / \mathrm{Mpj}$ -
Fas (lpr) mice by N-3 fatty acids, J. Am. Coll. Nutr. 24; 200-209.

Cadirci, E., Suleyman, H., Aksoy, H., Halici, Z., Ozgen, U., Koc, A., Ozturk, N. 2007 Effects of Onosmaarmeniacum root extract on ethanol induced oxidative stress in stomach tissue of rats. Chem. Biol. Interact., 170, 40-48.

Calam, J., Baron, J.H. 2001.ABC of the upper gastrointestinal tract. Pathophysiology of duodenal and gastric ulcer and gastric cancer, BMJ.( 323) 980-982

Calatayud, S., Barrachina, D., Esplugues, J.V. 2001. Nitric oxide: relation to integrity, injury, and healing of the gastric mucosa. Microsc Res Tech 53(5):325335.

Chandrasekar, B., Fernandes, G. 1994. Decreased Proinflammatory Cytokines and Increased Antioxidant EnzymeGene Expression by $\omega-3$ Lipids in Murine Lupus Nephritis, Biochem.Biophys. Res. Commun. 200, 893-898.

Chellappan, D.R., Arun, K. P., Brindha, P. 2016. Gastroprotective potential of hydro-alcoholic extract of Pattanga (Caesalpiniasappan Linn.) Journal of Ethnopharmacology DOI: http://dx. doi.org/10.1016/j.jep.2016.07.081

Chiu, W.C., Hou, Y.C., Yeh, C.L., Hu, Y.M., Yeh, S.L.2007. Effect of dietary fish oil supplementation on cellular adhesion molecule expression and tissue myeloperoxidase activity in diabetic mice with sepsis. Br J Nutr;97:685e91.

Cho, C.H. 2001. Current roles of nitric oxide in gastro intenstinal disorders. J Physiol Paris; 95: 253-6.

Cho, J.Y., Chi, S.G., Chun, H.S. 2011. Oral administration of docosahexaenoic acid 
attenuates colitis induced by dextran sulfate sodium in mice. MolNutr Food Res.;55(2):239-46.

da Silvaa, L.M., Allemanda, A., Mendes, D.A., Dos Santos, A.C., André, E., de Souza, L.M., et al. 2013. Ethanolic extract of roots from Arctiumlappa L. accelerates the healing of acetic acid induced gastric ulcer in rats: Involvement of the antioxidant system, Food Chem. Toxicol. (51) 179-187.

de Caterina, R., Cybulsky, M.I., Clinton, S.K., Gimbrone, M.A., Libby, P. 1994 The Omega-3 Fatty Acid Docosahexaenoate Reduces Cytokine-Induced Expression of Pro-atherogenic and Proinflammatory Proteins in Human Endothelial Cells, Arterioscler. Thromb. 14, 1829-1836.

Dey, A., Cederbaum, A.I. 2006.Alcohol and oxidative liver injury. Hepatology, 43 (Suppl. 1), S63-S74.

Dinarello,C.A. 2011. A clinical perspective of IL-1as the gatekeeper of inflammation. Eur J Immunol; 41:1203-1217.

Ding, H.L., Zhu, H.F., Dong, J.W., Zhu, W.Z., Yang, W.W., Yang ,H.T., et al. 2005. Inducible nitric oxide synthase contributes to intermittent hypoxia against ischemia/reperfusion injury. ActaPharmacol Sin; 26: 315-22.

Dursun, H., Bilici, M., Albayrak, F., Ozturk, C., Saglam, M.B., Alp, H.H., Suleyman, H. 2009.Antiulcer activity of fluvoxamine in rats and its effect on oxidant and antioxidant parameters in stomach tissue. BMC Gastroenterol., 9, 36.

Fortunato, J.J., Agostinho, F.R., Reus, G.Z., Petronilho, F.C., Dal-Pizzol, F., Quevedo, J.2006.Lipid peroxidative damage on malathion exposure in rats. Neurotox. Res., 9, 23-28.

Franke, A., Teyssen, S., Singer, M.V. 2005.Alcohol-related diseases of the esophagus and stomach. Dig Dis.;23(34):204-13.

Ganguly,K., Maity,P., Reiter,R.J., Swarnakar,S. 2005. Effect of melatonin on Secreted and induced matrix metalloproteinase 9 and 2 activity during prevention of indomethacin induced gastric ulcer.J.PinealRes.39,307-315.

Grimm, H., Mayer, K., Mayser, P., Eigenbrodt, E.2002. Regulatory potential of n-3 fatty acids in immunological and inflammatory processes. Br J Nutr;87 (Suppl. 1):S59e67.

Guo, J.S., Cho, C.H., Wang, W.H., Shen, X.Z., Cheng, C.L., Koo, M.W. 2003. Expression and activity patterns of three inducible enzymes in the healing of gastric ulcers in rats. Word $\mathbf{J}$ Gastroenterol; 9: 1767-71.

Halabi, M.F., Shakir ,R.M., Bardi, D.A., AlWajeeh, N.S., Ablat, A., Hassandarvish, P., et al. 2014. Gastroprotective activity of ethyl-4-[(3,5-di-tert-butyl-2hydroxybenzylidene) amino]benzoate against ethanol-induced gastric mucosal ulcer in rats. PLoS One.; 9(5):e95908.

Halliwell, B., Gutteridge, J.M.C. 2006.Free Radicals in Biology and Medicine. Clarendon Press, Oxford, UK.

Hasgul, R., Uysal, S., Haltas, H., Akyol, S., Yuksel, Y., et al. 2014. Protective effects of Ankaferd blood stopper on aspirin-induced oxidative mucosal damage in a rat model of gastric injury. ToxicolInd Health 30: 888-895. 
Junior, F.E., de Oliveira, D.R., Boligon, A.A., Athayde, M.L., Kamdem, J.P., Macedo, G.E., da Silva, G.F., de Menezes, I.R., Costa, J.G., Coutinho, H.D., Kerntopf, M.R., Posser, T. 2014. Protective effects of Croton campestris A. St-Hill in different ulcer models in rodents: evidence for the involvement of nitric oxide and prostaglandins. J Ethnopharmacol 153, 469-477.

Kandhare, A.D., Alam, J., Patil, M.V., Sinha, A., Bodhankar, S.L. 2016. Wound healing potential of naringin ointment formulation via regulating the expression of inflammatory, apoptotic and growth mediators in experimental rats. Pharmaceutical biology 54, 419432.

Katary, M.A., Salahuddin, A. 2017. Gastroprotective effect of Punicalagin against Ethanol-Induced Gastric Ulcer: the Possible Underlying Mechanisms. Biomark J., 3:1.

Komatsu, W., Ishihara, K., Murata, M., Saito, H., Shinohara, K. 2003. Docosahexaenoic acid suppresses nitric oxide production and inducible nitric oxide synthase expression in interferon plus lipopolysaccharide-stimulated murine macrophages by inhibiting the oxidative stress, Free Radic. Biol. Med. 34 (8) 1006-1016.

Kwiecien, S., Ptak-Belowska, A., KrzysiekMaczka, G., Targosz, A., Jasnos, K., Magierowski, M., et al. 2012.Asymmetric dethylarginine, an endogenous inhibitor of nitric oxide synthase, interacts with gastric oxidative metabolism and enhances stress-induced gastric lesions. J Physiol Pharmacol.; 63(5): 515-524. [PubMed].
Lawrence, T. 2009. The nuclear factor NFkappaB pathway in inflammation. Cold Spring Harb PerspectBiol 1: a001651.

Leung, F.W. 1994. Prostaglandins mediate fish oil protection against ethanol-induced gastric mucosal injury in rats. Dig Dis Sci.;39(4):893.

Liu, Y., Tian, X., Gou, L., Fu, X., Li, S., Lan ,N., et al. 2012. Protective effect of 1citrulline against ethanol-induced gastric ulcer in rats. Environ Toxicol Pharmacol.; 34(2):280-287.

Luiz-Ferreira, A. Cola, M., Barbastefano, V., et al. 2012.Healing, antioxidant and cytoprotective properties of Indigofera truxillensis in different models of gastric ulcer in rats. Int $\mathbf{J}$ Mol Sci. 2012;13(11):14973-14991.

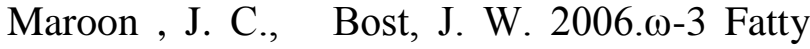
acids (fish oil) as an anti-inflammatory: an alternative to nonsteroidal antiinflammatory drugs for discogenic pain. Surgical Neurology (65) 326-331.

Mayurasakorn,

K.,Williams,J.J.,Ten,V.S.,Deckelbaum, R.J.2011.Docosahexaenoic acid: brain accretion and roles in neuroprotection after brain hypoxia and ischemia. Curr.Opin.Clin.Nutr.Metab.Care14,158 $-167$.

Mei, X., Xu, D., Xu, S., Zheng, Y., Xu ,S. 2012. Novel role of $\mathrm{Zn}$ (II)-curcumin in enhancing cell proliferation and adjusting pro-inflammatory cytokinemediated oxidative damage of ethanolinduced acute gastric ulcers. Chem. Biol. Interact., 197, 31-39.

Mesbah, L., Soraya, B., Narimane, S. , Jean, P.F. 2004. protective effect of flavonides against the toxicity of 
vinblastine cyclophosphamide and paracetamol by inhibition of lipid peroxydation and increase of liver glutathione. Haematol.7 (1): 59-67.

Mohammed, A., Janakiram, N. B., Brewer, M. et al., 2012. "Endogenous n-3 polyunsaturated fatty acids delay progression of pancreatic ductal adenocarcinoma in Fat-1-p48Cre/+LSL-KrasG12D/+mice," Neoplasia, vol. 14 , no. 12 , pp. 1249-1259,

Mohod, S. M., Amit D. Kandhare and Subhash L. Bodhankar, 2016. Gastroprotective potential of Pentahydroxy flavone isolated from Madhucaindica J. F. Gmel. leaves against acetic acidinduced ulcer in rats: the role of oxidoinflammatory and prostaglandins markers, Journal of Ethnopharmacology, http://dx.doi.org/ 10.1016/j.jep.2016.02.026

Montgomery, H.A.C., Dymock, J.F. 1961. The determination of nitrite in water. Analyst, 86: 414-416.

Nagai, N., Fukuhata ,T., Ito, Y., Usui, S., Hirano, K. 2009. Involvement of interleukin 18 in indomethacin-induced lesions of the gastric mucosa in adjuvant-induced arthritis rat. Toxicology, 255, 124-130.

Nagano, Y., Matsui, H., Shimokawa, O., Hirayama, A., Tamura, M., Nakamura, Y. et al., 2012. Rebamipide attenuates nonsteroidal anti-inflammatory drugs (NSAID) induced lipid peroxidation by the manganese superoxide dismutase (MnSOD) over expression in gastrointestinal epithelial cells, J. Physiol. Pharmacol. 63 137-142.
Nishida,K.,Ohta,Y.,Ishiguro,I.1998.Contributio $\mathrm{n}$ of NO synthases to neutrophil infiltration in the gastric mucosal lesions in rats with water immersion restraint stress. FEBS425,243-248.

Paget, G. E. ,Barnes, J. M. 1964. Toxicity test. In: Laurence, D. R. Bacharach, A. L.; editors. Evaluation of drug activities: Pharmacometric. London and New York: Academic press; 134-166.

Patterson, J.W., Lazarow, A. 1955. Determination of glutathione; Methods of Biochemical Analysis; 2: 259-278.

Renier, G., Skamene, E., de Sanctis, J., Radzioch, D. 1993. Dietary n-3 Polyunsaturated Fatty Acids Prevent the Development of Atherosclerotic Lesions in Mice: Modulation of Macrophage Secretory Activities, Arterioscler. Thomb. 13, 1515-1524.

Rozza, A.L., Meira de Faria, F., Souza Brito, A.R., Pellizzon, C.H. 2014. The gastroprotective effect of menthol: involvement of anti-apoptotic, antioxidant and anti-inflammatory activities. PLoS ONE, 9, e86686.

Salga, M.S., Ali, H.M., Abdulla, M.A., Abdelwahab, $\quad$ S.I. 2012. Gastroprotective activity and mechanism of novel dichloridozinc(II)-4-(2-(5-methoxybenzylideneamino) ethyl) piperazin-1-iumphenolate complex on ethanol-induced gastric ulceration. Chem. Biol. Interact., 195, 144-153.

Sangiovanni, E., Vrhovsek, U., Rossoni, G., Colombo, E., Brunelli, C., Brembati, L., et al. 2013. Ellagitannins from Rubus berries for the control of gastric 
inflammation: in vitro and in vivo studies. PLoS One.; 8(8): e71762.

Sarkate, A.P., Murumkar, P.R., Lokwani, D.K., Kandhare, A.D., Bodhankar, S.L., Shinde, D.B., Bothara, K.G. 2015. Design of selective TACE inhibitors using molecular docking studies: Synthesis and preliminary evaluation of anti-inflammatory and TACE inhibitory activity. SAR QSAR Environ Res 26, 905-923.

Sen, S. K., Asokkumar, M., Umamaheswari, A.T., Sivashanmugam, V. 2013. Subhadradevi, Antiulcerogenic effect of gallic acid in rats and its effect on oxidant and antioxidant parameters in stomach tissue, Indian J. Pharm. Sci. 75 149-155.

Song, C., Horrobin, D. 2004. Omega-3 fatty acid ethyl-eicosapentaenoate but notsoybeanoil, attenuates memory impairment induced by central il1betaadministration, J. Lipid Res. 45 1112-1121.

Song, Ji-W., Seo, C.-S., Tae-In Kim, Og-Sung Moon, Young-Suk Won, Hwa-Young Son, Jong-Keun Son, and Hyo-Jung Kwon(2016): Protective Effects of Manassantin A against Ethanol-Induced Gastric Injury in Rats. Biol. Pharm. Bull. 39, 221-229.

Souza, M.H., Lemos, H.P., Oliveira, R.B., Cunha, F.Q. 2004. Gastric damage andspecies of platelet activating factor in ulcerative colitis. Lipids 1996;31(Suppl.):S255e9.

Tatemichi ,M., Tsutomu,O., Nobuyuki S., Hiroshi, N., Minoru, S., Hiroyasu, E. 2003. Roles of inducible nitric oxide synthase in the development and healing of experimentally induced gastric ulcers. Int. J. Exp. Path. 84, 213-220.

Thorsen, K., Sóreide, J.A., Kvalóy, J.T., Glomsaker, T., Sóreide, K. 2013. Epidemiology of perforated peptic ulcer: Age- and gender-adjusted analysis of incidence and mortality, World J. Gastroenterol.( 19) 347-354.

Thyssen, E., Turk, J., Bohrer, A., Stenson, W.F.1996. Quantification of distinct molecular species of platelet activating factor in ulcerative colitis. Lipids;31(Suppl.):S255e9.

Verma, S., Kumar, V.L. 2016. Attenuation of gastric mucosal damage by artesunate in rat: Modulation of oxidative stress and NFkB mediated signaling. ChemicoBiological Interactions, doi: 10.1016/j.cbi.2016.07.027.

Wada, M., DeLong, C.J., Hong, Y.H., Rieke, C.J., Song, I., Sidhu, R.S., et al. 2007. Enzymes and receptors of prostaglandin pathways with arachidonic acid-derived versus eicosapentaenoic acid-derived substrates and products. J Biol Chem; 282: $22254 \mathrm{e} 66$.

Wallace, J.L., Keenan, C.M., Granger, N. 1990. Gastric ulceration induced by nonsteroidal anti-inflammatory drugs is a neutrophil-dependent process, Am. J. Physiol. 259; 462-467.

Warzecha, Z., Ceranowicz, P., Dembinski, M., Cieszkowski, M.J., Ginter, G., Ptakbelowska, A., Dembinski, A. 2014 .Involvement of cyclooxygenase-1 and cyclooxygenase- 2 activity in the therapeutic effect of ghrelin in the course of ethanol-induced gastric ulcers in rats. Journal Of Physiology And Pharmacology, 65, 1, 95-106. 
Xu, J.B., Yuan, X.F., Lang, P.Z. 1997. Determination of catalase activity and catalase inhibition by ultraviolet spectrophtometry. Chinese Environ. Chem. 16: pp. 73-76.

Yang, T.C., Zhang, S.W., Sun, L.N., Wang, H., Ren, A.M. 2008.Magnolol attenuates sepsis induced gastrointestinal dysmotility in rats by modulating inflammatory mediators. World journal of gastroenterology 14, 7353-7360.

Yao, J. 2015. Tiao He Yi Wei Granule, a Traditional Chinese Medicine, against Ethanol-Induced Gastric Ulcer in Mice. Evid Based Complement Alternat Med, 647283.

Yoshihara, T. , Shimada, K., Fukao, K., Sai, E., Sato-Okabayashi, Y., Matsumori,R., Shiozawa,T., Alshahi, H., Miyazaki,T., Tada, N., Daida,H. 2015. Omega 3 polyunsaturated fatty acids suppress the development of aortic aneurysmsthrough the inhibition of macrophage-mediated inflammation, Circ. J. 791470-1478. 